\title{
Soil water regulates the control of photosynthesis on diel hysteresis between soil respiration and temperature in a desert shrubland
}

\author{
Ben Wang ${ }^{1,2,3}$, Tian Shan Zha ${ }^{1,2}$, Xin Jia ${ }^{1,2,3}$, Jin Nan Gong ${ }^{3}$, Charles Bourque ${ }^{4}$, Wei Feng ${ }^{1,2}$, Yun Tian ${ }^{1,2}$, Bin Wu ${ }^{1,2}$, \\ Yu Qing Zhang ${ }^{1,2}$, and Heli Peltola ${ }^{3}$ \\ ${ }^{1}$ Yanchi Research Station, School of Soil and Water Conservation, Beijing Forestry University, Beijing 100083, PR China \\ ${ }^{2}$ Key Laboratory of State Forestry Administration on Soil and Water Conservation, Beijing Forestry University, Beijing, China \\ ${ }^{3}$ School of Forest Sciences, University of Eastern Finland, P.O. Box 111, 80101 Joensuu, Finland \\ ${ }^{4}$ Faculty of Forestry and Environmental Management, University of New Brunswick, P.O. Box 4400, 28 Dineen Drive, \\ Fredericton, New Brunswick, E3B 5A3, Canada
}

Correspondence to: Tian Shan Zha (tianshanzha@bjfu.edu.cn)

Received: 14 October 2016 - Discussion started: 24 October 2016

Revised: 15 July 2017 - Accepted: 26 July 2017 - Published: 7 September 2017

\begin{abstract}
Explanations for the occurrence of hysteresis (asynchronicity) between diel soil respiration $\left(R_{\mathrm{S}}\right)$ and soil temperature $\left(T_{\mathrm{S}}\right)$ have evoked both biological and physical mechanisms. The specifics of these explanations, however, tend to vary with the particular ecosystem or biome being investigated. So far, the relative degree of control of biological and physical processes on hysteresis is not clear for drylands. This study examined the seasonal variation in diel hysteresis and its biological control in a desert-shrub ecosystem in northwest (NW) China. The study was based on continuous measurements of $R_{\mathrm{S}}$, air temperature $\left(T_{\mathrm{a}}\right)$, temperature at the soil surface and below $\left(T_{\text {surf }}\right.$ and $\left.T_{\mathrm{S}}\right)$, volumetric soil water content (SWC), and photosynthesis in a dominant desert shrub (i.e., Artemisia ordosica) over an entire year in 2013. Trends in diel $R_{\mathrm{S}}$ were observed to vary with SWC over the growing season (April to October). Diel variations in $R_{\mathrm{S}}$ were more closely associated with variations in $T_{\text {surf }}$ than with photosynthesis as SWC increased, leading to $R_{\mathrm{S}}$ being in phase with $T_{\text {surf }}$, particularly when $S W C>0.08 \mathrm{~m}^{3} \mathrm{~m}^{-3}$ (ratio of SWC to soil porosity $=0.26$ ). However, as SWC decreased below $0.08 \mathrm{~m}^{3} \mathrm{~m}^{-3}$, diel variations in $R_{\mathrm{s}}$ were more closely related to variations in photosynthesis, leading to pronounced hysteresis between $R_{\mathrm{S}}$ and $T_{\text {surf }}$. Incorporating photosynthesis into a $Q_{10}$-function eliminated $84.2 \%$ of the observed hysteresis, increasing the overall descriptive capability of the function. Our findings highlight a high degree of control by photosynthesis and SWC in regulating seasonal variation in diel hysteresis between $R_{\mathrm{S}}$ and temperature.
\end{abstract}

\section{Introduction}

Diel hysteresis (asynchronicity) between soil respiration $\left(R_{\mathrm{S}}\right)$ and soil temperature $\left(T_{\mathrm{S}}\right)$ is widely documented for forests (Tang et al., 2005; Gaumont-Guay et al., 2006; RiverosIregui et al., 2007; Stoy et al., 2007; Vargas and Allen, 2008; Jia et al., 2013), grasslands (Carbone et al., 2008; BarronGafford et al., 2011), and desert ecosystems (Wang et al., 2014; Feng et al., 2014). Diel hysteresis, which appears as an elliptical loop in the relationship between $R_{\mathrm{S}}$ and $T_{\mathrm{s}}$, is difficult to model with theoretical functions, such as the $Q_{10}$, Lloyd-Taylor, Arrhenius, or van't Hoff functions (Lloyd and Taylor, 1994; Winkler et al., 1996; Davidson et al., 2006; Phillips et al., 2011; Oikawa et al., 2014), leading to an inadequate understanding of temperature sensitivity in $R_{\mathrm{S}}$ (Gaumont-Guay et al., 2008; Phillips et al., 2011; Darenova et al., 2014). Therefore, in order to accurately predict soil carbon dioxide $\left(\mathrm{CO}_{2}\right)$ fluxes and their responses to climate change, it is necessary to understand the biophysical mechanisms that have a role in controlling seasonal variation in diel hysteresis.

Over decades of research, two main processes have been reported to relate to diel hysteresis between $R_{\mathrm{S}}$ and $T_{\mathrm{s}}$. One is associated with the physical processes of heat and gas transport in soils (Vargas and Allen, 2008; Phillips et al., 2011; Zhang et al., 2015). Generally, soil $\mathrm{CO}_{2}$ fluxes are measured at the soil surface and are related to temperatures in the soil. Transport of $\mathrm{CO}_{2}$ gas to the soil surface takes time to oc- 
cur, which may cause delays to appear in observed respiration rates, causing hysteretic loops to form between $R_{\mathrm{S}}$ and $T_{\mathrm{S}}$ (Zhang et al., 2015). The other is associated with the biological process of photosynthate supply (Tang et al., 2005; Kuzyakov and Gavrichkova, 2010; Vargas et al., 2011; Wang et al., 2014). Beyond the control of temperature, soil $\mathrm{CO}_{2}$ fluxes have been associated with plant photosynthesis. Photosynthesis usually peaks at midday (e.g., 11:00-13:00), providing substrate for belowground roots and rhizospheremicrobe respiration, but oscillates out of phase with $T_{\mathrm{s}}$, usually peaking in the afternoon (e.g., 14:00-16:00). Such influences of current photosynthesis could lead to the formation of hysteretic loops in the relationship between $R_{\mathrm{S}}$ and $T_{\mathrm{S}}$. These studies highlight the need to consider the inherent role of photosynthesis for a more accurate interpretation of $R_{\mathrm{S}}$ (Tang et al., 2005; Kuzyakov and Gavrichkova, 2010; Vargas et al., 2011). Physical and biological processes that relate to substrates and production transport of carbon (C) in plants and soils are not mutually exclusive and both likely play crucial roles in affecting diel variation in $R_{\mathrm{S}}$ (Stoy et al., 2007; Phillips et al., 2011; Zhang et al., 2015; Song et al., 2015a, b).

Diel hysteresis between $R_{\mathrm{S}}$ and $T_{\mathrm{S}}$ has been shown to vary seasonally with soil water content (SWC; Tang et al., 2005; Riveros-Iregui et al., 2007; Carbone et al., 2008; Vargas and Allen, 2008; Ruehr et al., 2009; Wang et al., 2014). However, the influences of SWC on diel hysteresis are not uniform. Based on the Millington-Quirk model, high SWC blocks $\mathrm{CO}_{2}$ gas and thermal diffusion (Millington and Quirk, 1961), resulting in large hysteresis loops (Riveros-Iregui et al., 2007; Zhang et al., 2015). In contrast, other studies have reported that low SWC and high water vapor pressure deficits can promote partial stomata closure, which leads to higher photosynthesis in the morning (e.g., 9:00-10:00) and suppressed photosynthesis in mid-afternoon, leading to pronounced hysteresis during dry periods (Tang et al., 2005; Vargas and Allen, 2008; Carbone et al., 2008; Wang et al., 2014). Clearly to understand the causes of diel hysteresis the role of SWC needs to be closely evaluated.

Drylands cover a quarter of the earth's land surface and play an important role in the global C cycle (Safriel and Adeel, 2005; Austin, 2011; Poulter et al., 2014). Many studies in forest ecosystems are based on the application of physical soil $\mathrm{CO}_{2}$ and heat transport models and evaluate the influences of $\mathrm{SWC}$ on $\mathrm{CO}_{2}$ gas and thermal diffusion (RiverosIregui et al., 2007; Phillips et al., 2011; Zhang et al., 2015). In general, many of these studies conclude that diel hysteresis is the result of physical processes alone. Few studies have evaluated the causes of diel hysteresis in drylands. Currently, it is not clear to what degree physical and biological processes control hysteresis in drylands.

Drylands are characterized with low productivity. As weak organic C-storage pools (West et al., 1994; Lange, 2003), drylands are noted for their large contribution of autotrophic production of $\mathrm{CO}_{2}$. The autotrophic component of $R_{\mathrm{S}}$ occurs as a direct consequence of root respiration, which is firmly coupled (within several hours) to recent photosynthesis (Liu et al., 2006; Baldocchi et al., 2006; Högberg and Read, 2006; Bahn et al., 2009; Kuzyakov and Gavrichkova, 2010). Consequently, photosynthesis may govern the level of variation in asynchronicity between $R_{\mathrm{S}}$ and $T_{\mathrm{S}}$ in drylands. In drylands, especially in desert ecosystems characterized by sandy soils with high soil porosity, the influence of SWC on gas diffusion is likely nominal. As a rule, most of the available water is used directly in sustaining biological activity in drylands (Noy-Meir, 1973). Under drought conditions, stomata closure in plants at midday reduces water losses, resulting in a corresponding suppression of photosynthesis (Jia et al., 2014). Such changes in diel patterns of photosynthesis likely result in modifications of patterns in $R_{\mathrm{S}}$, leading to hysteresis between $R_{\mathrm{S}}$ and $T_{\mathrm{s}}$. Soil water content likely regulates photosynthesis and, in so doing, causes hysteresis between $R_{\mathrm{S}}$ and $T_{\mathrm{S}}$ to vary over the growing season.

In this study, we hypothesize that (1) photosynthesis has a high degree of control in the formation of hysteretic loops between $R_{\mathrm{S}}$ and $T_{\mathrm{S}}$ and (2) SWC regulates this control and its variation over the growing season. The main objectives of this research were to (1) assess biological controls on diel hysteresis between $R_{\mathrm{S}}$ and $T_{\mathrm{S}}$, (2) explore the causes that lead to variation in seasonal variation in diel hysteresis, and (3) understand SWC's role in influencing hysteresis. To undertake this work, we measured $R_{\mathrm{S}}, \mathrm{SWC}, T_{\mathrm{S}}$, and photosynthesis in a dominant desert shrub on a continuous basis for 2013.

\section{Materials and methods}

\subsection{Site description}

The study was conducted at Yanchi Research Station of Beijing Forestry University, Ningxia, northwest China $\left(37^{\circ} 42^{\prime} 31^{\prime \prime} \mathrm{N}, 107^{\circ} 13^{\prime} 37^{\prime \prime} \mathrm{E} ; 1550 \mathrm{~m}\right.$ a.s.l.). The station is located at the southern edge of the Mu Us desert in the transition between the arid and semi-arid climatic zones. Based on 51 years of data (1954-2004) from the meteorological station at Yanchi, the mean annual air temperature at the station was $8.1^{\circ} \mathrm{C}$ and the mean annual total precipitation (PPT, $\mathrm{mm}$ ) was $292 \mathrm{~mm}$ (ranging between 250 and $350 \mathrm{~mm}$ ), $63 \%$ of which fell in late summer (i.e., July-September; Wang et al., 2014; Jia et al., 2014). Annual potential evaporation was on average $5.5 \mathrm{~kg} \mathrm{~m}^{-2} \mathrm{~d}^{-1}$ (Gong et al., 2016). The soil at the research station was of a sandy type, with a bulk density of $1.6 \mathrm{~g} \mathrm{~cm}^{-3}$. The total soil porosity within $0-2$ and $5-25 \mathrm{~cm}$ depths was 50 and $38 \%$, respectively. Soil organic matter, soil nitrogen, and $\mathrm{pH}$ were $0.21-2.14 \mathrm{~g} \mathrm{~kg}^{-1}, 0.08-2.10$, and 7.76-9.08, respectively (Wang et al., 2014; Jia et al, 2014). The vegetation was regenerated from aerial seeding applied in 1998 and is currently dominated by a semi-shrub species cover of Artemisia ordosica, averaging about $50 \mathrm{~cm}$ tall with 
a canopy size of about $80 \mathrm{~cm} \times 60 \mathrm{~cm}$ (for additional site description, consult Jia et al., 2014, and Wang et al., 2014, 2015).

\subsection{Soil respiration and photosynthesis measurement}

Two permanent polyvinyl chloride soil collars were initially installed on a small fixed sand dune in March 2012. Collar dimensions were $20.3 \mathrm{~cm}$ in diameter and $10 \mathrm{~cm}$ in height, with $7 \mathrm{~cm}$ inserted into the soil. One collar was set on bare land with an opaque chamber (LI-8100-104, Nebraska, USA) and the other over an Artemisia ordosica plant $(\sim 10 \mathrm{~cm}$ tall) with a transparent chamber (LI-8100-104C). Soil respiration ( $\mu \mathrm{mol} \mathrm{CO}_{2} \mathrm{~m}^{-2} \mathrm{~s}^{-1}$ ) was directly estimated from $\mathrm{CO}_{2}$-flux measurements obtained with the opaque-chamber system. Photosynthetic rates $\left(\mu \mathrm{mol} \mathrm{CO} \mathrm{CO}^{-2} \mathrm{~s}^{-1}\right)$ of the selected plants were determined as the difference in $\mathrm{CO}_{2}$ fluxes obtained with the transparent and opaque chambers.

Continuous measurements of $\mathrm{CO}_{2}$ fluxes $\left(\mu \mathrm{mol} \mathrm{CO} \mathrm{m}^{-2} \mathrm{~s}^{-1}\right)$ were made in situ with a Li-8100 $\mathrm{CO}_{2}$ gas analyzer and a LI-8150 multiplexer (LI-COR, Nebraska, USA) connected to each chamber. Instrument maintenance was carried out bi-weekly during the growing season, including removing plant regrowth in the opaque-chamber installation and cleaning to avoid blackout conditions associated with the transparent chamber. Measurement time for each chamber was $3 \mathrm{~min}$ and $15 \mathrm{~s}$, including a 30-second pre-purge, 45 -second post-purge, and 2 min measurement period.

\subsection{Measurements of temperatures, soil water content, and other environmental factors}

Hourly soil temperature $\left(T_{\mathrm{s}},{ }^{\circ} \mathrm{C}\right)$ and volumetric SWC $\left(\mathrm{m}^{3} \mathrm{~m}^{-3}\right)$ at a $10 \mathrm{~cm}$ depth were measured simultaneously about $10 \mathrm{~cm}$ from the chambers using a LI-8150-203 temperature and $\mathrm{EC}_{\mathrm{H}_{2} \mathrm{O}}$ soil-moisture sensor (LI-COR, Nebraska, USA; see Wang et al., 2014). Other environmental variables were recorded every half hour using sensors mounted on a $6 \mathrm{~m}$ tall eddy-covariance tower approximately $800 \mathrm{~m}$ from our soil $\mathrm{CO}_{2}$-flux measurement site. Air temperature $\left(T_{\mathrm{a}},{ }^{\circ} \mathrm{C}\right)$ was measured with a thermohygrometer (HMP155A, Vaisala, Finland). Soil-surface temperature $\left(T_{\text {surf }},{ }^{\circ} \mathrm{C}\right)$ was measured with an infrared-emission sensor (model SI-111, Campbell Scientific Inc., USA). Incident photosynthetically active radiation (PAR) was measured with a light-quantum sensor (PAR-LITE, Kipp and Zonen, the Netherlands) and PPT, with three tipping-bucket rain gages (model TE525MM, Campbell Scientific Inc., USA) placed $50 \mathrm{~m}$ from the tower (see Jia et al., 2014).

\subsection{Data processing and statistical analysis}

In this study, $\mathrm{CO}_{2}$-flux measurements were screened by means of limit checking; i.e., hourly $\mathrm{CO}_{2}$-flux data $<-30$ or $>15 \mu \mathrm{mol} \mathrm{CO} \mathrm{CO}^{-2} \mathrm{~s}^{-1}$ were considered to be anomalous as a result of, for instance, gas leakage or plant damage by insects and removed from the dataset (Wang et al., 2014, 2015). After limit checking, hourly $\mathrm{CO}_{2}$ fluxes greater than three times the standard deviation from the calculated mean of 5 days' worth of flux data were likewise removed. Quality control and instrument failure together resulted in $5 \%$ loss of hourly fluxes for all chambers, $4 \%$ for temperatures, and $8 \%$ for SWC (Fig. 1). Differences in mean annual $T_{\mathrm{S}}$ and SWC between the two chambers were $0.01{ }^{\circ} \mathrm{C}$ and $0.003 \mathrm{~m}^{3} \mathrm{~m}^{-3}$, respectively.

The $Q_{10}$ function (e.g., Eq. 1) was used here to describe the response of $R_{\mathrm{S}}$ to temperature. Earlier studies have shown strong correlation between basal rate of $R_{\mathrm{S}}$ and photosynthesis (Irvine et al., 2005; Sampson et al., 2007). Response of $R_{\mathrm{S}}$ to changes in photosynthesis was, in turn, characterized as a linear function (Eq. 2). Interaction between photosynthesis and temperature on $R_{\mathrm{S}}$ was conveyed through Eq. (3). The instantaneous relative importance (RI) of photosynthesis and temperature on $R_{\mathrm{S}}$ over the growing season was calculated with a correlation-based ratio (see Eq. 4). The importance of photosynthesis on $R_{\mathrm{s}}$ increases with a corresponding increase in RI:

$$
\begin{aligned}
& R_{\mathrm{S}}=R_{10} \times Q_{10}^{(T-10) / 10}, \\
& R_{\mathrm{s}}=a \times P+b, \\
& R_{\mathrm{S}}=(a \times P+b) \times c^{(T-10) / 10}, \\
& \mathrm{RI}=\frac{\rho_{\mathrm{p}}}{\rho_{t}},
\end{aligned}
$$

where $R_{10}$ is the respiration at $10^{\circ} \mathrm{C} ; Q_{10}$ is the temperature sensitivity of respiration; $T$ is temperature; $P$ is photosynthesis $\left(\mu \mathrm{mol} \mathrm{CO} \mathrm{CO}^{-2} \mathrm{~s}^{-1}\right) ; a, b$, and $c$ are regression coefficients; and $\rho_{\mathrm{p}}$ and $\rho_{\mathrm{t}}$ are the correlation coefficients between photosynthesis and $R_{\mathrm{S}}$ and temperature and $R_{\mathrm{S}}$, respectively.

Pearson correlation analysis was used to calculate the correlation coefficient between temperature or photosynthesis and $R_{\mathrm{s}}$. Cross-correlation analysis was used to estimate hysteresis in the relationship between temperature and $R_{\mathrm{S}}$ and photosynthesis and $R_{\mathrm{S}}$. We used root-mean-square error (RMSE) and the coefficient of determination $\left(R^{2}\right)$ as criteria in evaluating function performance. To evaluate seasonal variation in diel hysteresis, the mean monthly daily cycles of $R_{\mathrm{s}}, T_{\mathrm{a}}, T_{\text {surf }}, T_{\mathrm{s}}$, and photosynthesis were generated by averaging their hourly means at a given hour over a particular month (Table 1). Exponential and linear regression was used to evaluate the influence of SWC on the control of photosynthesis on temperature- $R_{\mathrm{S}}$ hysteresis. Likewise, influences of SWC on diel hysteresis was examined during a wet month with high rainfall and adequate SWC (July, $\mathrm{PPT}=117.9 \mathrm{~mm}$ ) and a dry month with low rainfall and inadequate SWC (August, PPT $=10.9 \mathrm{~mm}$; Wang et al., 2014). In order to evaluate the influence of photosynthesis on diel hysteresis in the temperature- $R_{\mathrm{S}}$ relationship, we compared the time lag (in hours) between measured and modeled $R_{\mathrm{S}}$ by means of Eqs. (1) through (3) with a 1-day moving window 

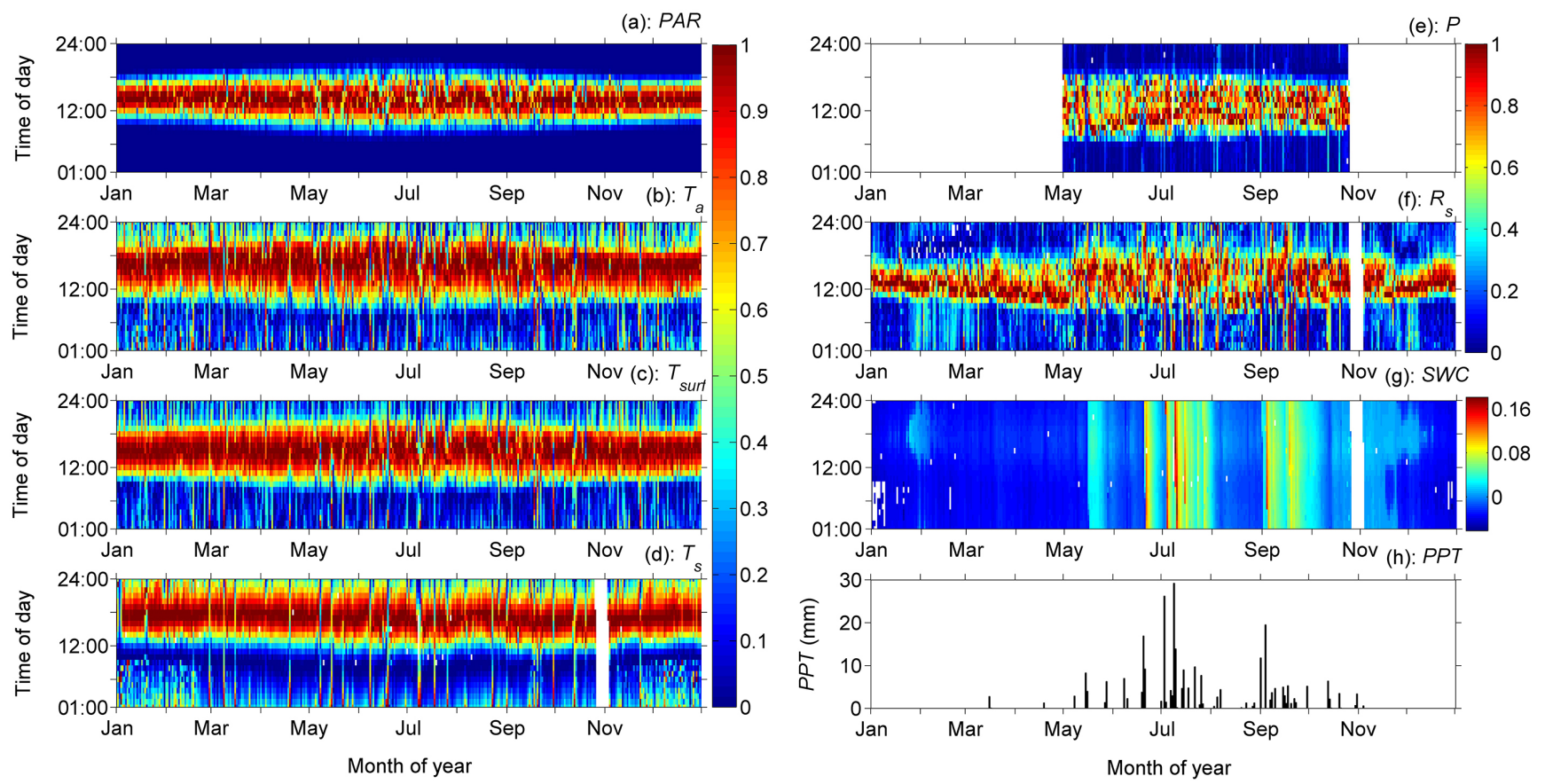

Figure 1. Seasonal variation in incident photosynthetically active radiation (PAR), temperature (i.e., air $\left(T_{\mathrm{a}}\right)$, soil-surface $\left(T_{\text {surf }}\right)$, and soil temperatures $\left(T_{\mathrm{S}}\right)$ ), photosynthesis $(P)$, and soil respiration $\left(R_{\mathrm{S}}\right)$ at an Artemisia ordosica-dominated site, and seasonal variation in soil water content (SWC) and precipitation (PPT) for 2013. Hourly PAR, $T_{\mathrm{a}}, T_{\mathrm{surf}}, T_{\mathrm{S}}, R_{\mathrm{S}}$, and $P$ are normalized against all values for each day. Each hourly value ( $y$ axis) for each day ( $x$ axis) is shown as a value of 1 through $0 ; 1$ denotes the peak value for a given day and 0 is the daily minimum value.

Table 1. Analysis of mean monthly diel cycles of soil respiration $\left(R_{\mathrm{S}}\right)$, air temperature $\left(T_{\mathrm{a}}\right)$, soil-surface temperature $\left(T_{\text {surf }}\right)$, soil temperature at a $10 \mathrm{~cm}$ depth $\left(T_{\mathrm{S}}\right)$, and photosynthesis $(P)$ in a dominant desert-shrub ecosystem, including correlation coefficients and time lag times in $R_{\mathrm{S}}$ vs. $T_{\mathrm{a}}, T_{\mathrm{surf}}, T_{\mathrm{S}}$, and $P$ cycles. Statistically significant Pearson's correlation coefficients $(r ; p<0.05)$ are denoted in bold.

\begin{tabular}{llrrrrrrrrrrrr}
\hline & & Jan & Feb & Mar & Apr & May & Jun & Jul & Aug & Sep & Oct & Nov & Dec \\
\hline$R_{\mathrm{S}}-T_{\mathrm{a}}$ & Lag & 2 & 4 & 3 & 3 & 1 & 1 & 1 & 2 & 1 & 1 & 1 & 1 \\
& $r$ & $\mathbf{0 . 6 4}$ & 0.25 & $\mathbf{0 . 4 9}$ & $\mathbf{0 . 4 6}$ & $\mathbf{0 . 8 5}$ & $\mathbf{0 . 8 5}$ & $\mathbf{0 . 9 3}$ & $\mathbf{0 . 7 6}$ & $\mathbf{0 . 9 4}$ & $\mathbf{0 . 8 9}$ & $\mathbf{0 . 7 8}$ & $\mathbf{0 . 7 7}$ \\
$R_{\mathrm{S}}-T_{\text {surf }}$ & Lag & 1 & 2 & 2 & 2 & 0 & 0 & 0 & 1 & 0 & 0 & 1 & 1 \\
& $r$ & $\mathbf{0 . 8 2}$ & $\mathbf{0 . 5 7}$ & $\mathbf{0 . 7 5}$ & $\mathbf{0 . 7 2}$ & $\mathbf{0 . 9 6}$ & $\mathbf{0 . 9 6}$ & $\mathbf{0 . 9 8}$ & $\mathbf{0 . 8 7}$ & $\mathbf{0 . 9 8}$ & $\mathbf{0 . 9 7}$ & $\mathbf{0 . 8 9}$ & $\mathbf{0 . 8 7}$ \\
$R_{\mathrm{S}}-T_{\mathrm{S}}$ & Lag & 4 & 5 & 5 & 5 & 3 & 3 & 2 & 4 & 2 & 2 & 4 & 4 \\
& $r$ & -0.06 & -0.31 & -0.06 & -0.07 & $\mathbf{0 . 5 4}$ & $\mathbf{0 . 5 8}$ & $\mathbf{0 . 8 0}$ & 0.31 & $\mathbf{0 . 7 7}$ & $\mathbf{0 . 6 5}$ & 0.23 & 0.12 \\
$R_{\mathrm{S}}-P$ & Lag & & & & & -1 & -1 & -2 & 0 & -1 & -1 & & \\
& $r$ & & & & & $\mathbf{0 . 8 4}$ & $\mathbf{0 . 8 3}$ & $\mathbf{0 . 8 2}$ & $\mathbf{0 . 9 4}$ & $\mathbf{0 . 8 6}$ & $\mathbf{0 . 8 8}$ & & \\
\hline
\end{tabular}

and a 1-day time step over the growing season (April to October). Modeled $R_{\mathrm{S}}$ was calculated using the fitted parameters of each function and the measured hourly $T_{\text {surf }}$ and photosynthesis for each day. All statistical analyses were performed in MATLAB, with a significance level of 0.05 (R2010b, Mathworks Inc., Natick, MA, USA).

\section{Results}

\subsection{Diel patterns of soil respiration, photosynthesis, and environmental factors}

Incident photosynthetically active radiation, $T_{\mathrm{a}}, T_{\text {surf }}$, and $T_{\mathrm{s}}$ exhibited distinctive daily patterns over the year (Fig. 1a-d), peaking at $\sim 12: 00$ (local time, LT), $\sim 16: 00, \sim 14: 00$, and $\sim$ 17:00, respectively (Fig. 1a-d). Unlike the environmental factors, daily patterns in $R_{\mathrm{S}}$ remained constant over the nongrowing part of the year, peaking at 11:00-13:00, and highly variable during the growing season of the year (April to Oc- 


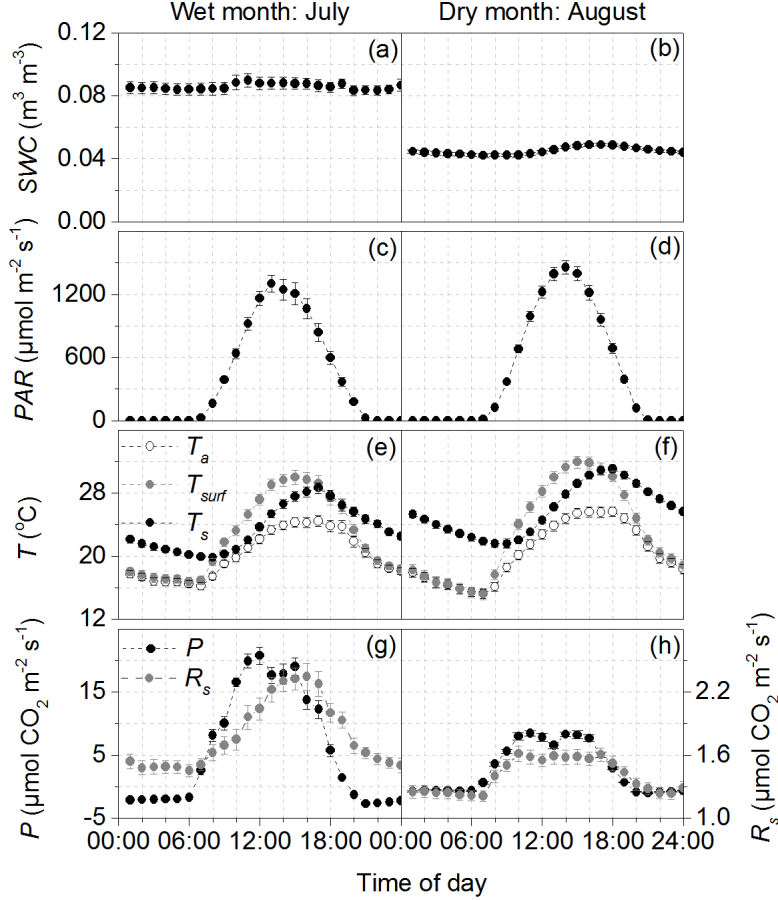

Figure 2. Mean monthly diel cycle of soil water content (SWC), incident photosynthetically active radiation (PAR), temperature (i.e., air $\left(T_{\mathrm{a}}\right)$, soil-surface $\left(T_{\text {surf }}\right)$, and soil temperatures $\left.\left(T_{\mathrm{S}}\right)\right)$, soil respiration $\left(R_{\mathrm{S}}\right)$, and photosynthesis $(P)$ at an Artemisia ordosicadominated site during a wet and dry month. Each point is the monthly mean for a particular time of day. Bars represent standard errors.

tober), peaking between 10:00 and 16:00 (Fig. 1f). Similar to $R_{\mathrm{S}}$ during the growing season, diel patterns of photosynthesis were also highly variable, peaking between 10:00 and 16:00 (Fig. 1e).

Diel patterns of monthly mean $R_{\mathrm{S}}$ were similar to those of $T_{\text {surf }}$ during the wet month and similar to those of photosynthesis during the dry month (Fig. 2g, h). During the wet month (July), monthly mean diel $R_{\mathrm{S}}$ was out of phase with photosynthesis, but in phase with $T_{\text {surf }}$ (Fig. $2 \mathrm{~g}$ ). Soil respiration peaked at 16:00, exhibiting similar timing to $T_{\text {surf }}$ (i.e., 15:00), but $4 \mathrm{~h}$ later than photosynthesis (peaking at 12:00; Fig. $2 \mathrm{~g}$ ). During the dry month (August), diel $R_{\mathrm{S}}$ was generally in phase with photosynthesis but out of phase with $T_{\text {surf }}$ (Fig. 2h). Both photosynthesis and $R_{\mathrm{s}}$ plateaued between 10:00 and 16:00, whereas $T_{\text {surf }}$ peaked at 15:00 (Fig. 2h).

\subsection{Control of photosynthesis and temperature on diel soil respiration}

Among temperatures at the three levels, $T_{\text {surf }}$ correlated the strongest with $R_{\mathrm{S}}$ due to the high $R^{2}$ with monthly mean diel $R_{\mathrm{S}}$ (Table 1). Over the growing season, monthly mean diel $R_{\mathrm{S}}$ correlated fairly well with photosynthesis (Table 1 ). The response of $R_{\mathrm{S}}$ to temperature and photosynthesis was

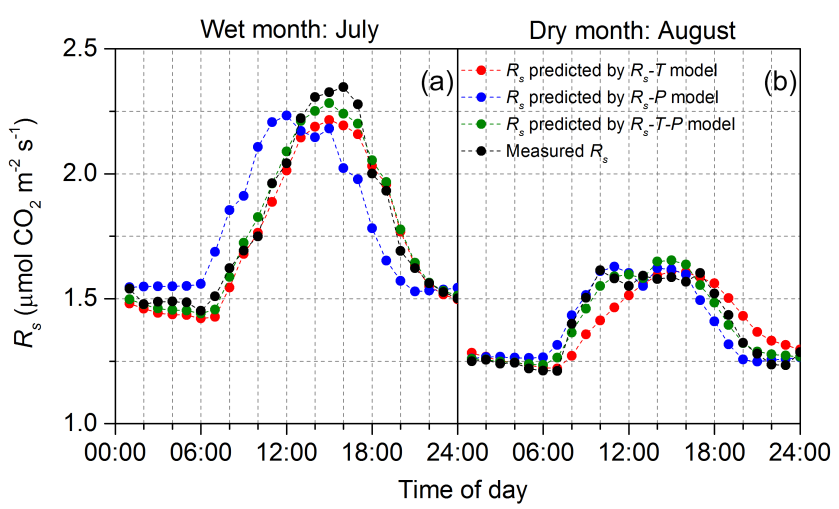

Figure 3. Diel variation of measured soil respiration $\left(R_{\mathrm{S}}\right)$ and modeled $R_{\mathrm{S}}$ by using temperature and photosynthesis as input variables in the calculation of $R_{\mathrm{S}}$ for both a wet and dry month (i.e., July and August, respectively); $R_{\mathrm{S}}-T$ function (Eq. 1), $R_{\mathrm{S}}-P$ function (Eq. 2), and $R_{\mathrm{S}}-T-P$ function (Eq. 3).

shown to be affected by SWC (Table 2, Fig. 3). During the wet month, $T_{\text {surf }}$ alone explained $97 \%$ of the variation in diel $R_{\mathrm{S}}$ (via Eq. 1), whereas photosynthesis explained $67 \%$ of the variation (Table 2, Fig. 3a). However, during the dry month, photosynthesis explained $88 \%$ of the variation in diel $R_{\mathrm{S}}$ (via Eq. 2), whereas $T_{\text {surf }}$ explained $76 \%$ of the variation (Fig. 3b, Table 2). Irrespective of dry or wet periods, $T_{\text {surf }}$ and photosynthesis together explained over $90 \%$ of the diel variation in $R_{\mathrm{S}}$ (via Eq. 3; see Fig. 3 and Table 2). On the whole, RI varied as a function of SWC, decreasing whenever SWC increased (Fig. 4).

\subsection{Effects of soil water content and photosynthesis on diel hysteresis in temperature- $\boldsymbol{R}_{\mathrm{s}}$ relationship}

During the wet month, hysteresis was not observed to occur in the monthly mean $T_{\text {surf }}-R_{\mathrm{S}}$ relationship, whereas 2-hour lags were found to occur in the photosynthesis $-R_{\mathrm{S}}$ relationship (Table 1; Fig. 3a). During the dry month, the opposite was observed, where 1-hour lags were found to occur in the $T_{\text {surf }}-R_{\mathrm{S}}$ relationship (Table 1, Fig. 3b). Over the growing

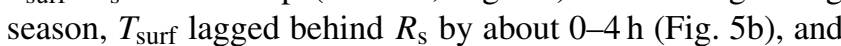
$R_{\mathrm{S}}$ lagged behind photosynthesis by about the same amount (Fig. 5c). This led to time lags between measured and modeled $R_{\mathrm{S}}$ regardless of the variable, $T_{\mathrm{surf}}$, or photosynthesis, resulting in about $26 \%$ of the days of the growing season (accounting for 184 days, in total) having no time lag (Fig. 5e, f). However, taking into account both $T_{\text {surf }}$ and photosynthesis as input variables in the definition of $R_{\mathrm{S}}$ (via Eq. 3), time lags between measured and modeled $R_{\mathrm{S}}$ were mostly eliminated (Fig. 5a, d), with $84 \%$ of the days of the growing season displaying no time lag.

Diel hysteresis in both relationships (i.e., $T_{\mathrm{surf}}-R_{\mathrm{s}}$ and photosynthesis- $R_{\mathrm{S}}$ ) was shown to be affected by SWC (Fig. 6). Over the growing season, diel hysteresis between $R_{\mathrm{S}}$ and $T_{\text {surf }}$ was linearly related to SWC in a downward 
Table 2. Regressions based on the $Q_{10}$, linear, and $Q_{10}$-linear functions of soil respiration $\left(R_{\mathrm{S}}\right)$ for both a wet (July) and dry month (August) in 2013. Variables $T_{\text {surf }}\left({ }^{\circ} \mathrm{C}\right)$ refers to the soil-surface temperature, $P$ photosynthesis in the dominant shrub layer, $R^{2}$ the coefficient of determination, and RMSE the root-mean-square error.

\begin{tabular}{llll}
\hline & Model & Wet month: July & Dry month: August \\
\hline$R_{\mathrm{S}}-T$ & $Q_{10}$ & $R_{\mathrm{S}}=1.13 \times 1.4^{\frac{T_{\text {surf }}-10}{10}}$ & $R_{\mathrm{S}}=1.12 \times 1.1^{\frac{T_{\text {surf }}-10}{10}}$ \\
& & $R^{2}=0.97$ & $R^{2}=0.76$ \\
$R_{\mathrm{S}}-P$ & RMSE $=0.0521$ & $\mathrm{RMSE}=0.0796$ \\
& Linear & $R_{\mathrm{S}}=0.03 \times P+1.61$ & $R_{\mathrm{S}}=0.04 \times P+1.29$ \\
& & $R^{2}=0.67$ & $R^{2}=0.88$ \\
& & $\mathrm{RMSE}=0.1889$ & $\mathrm{RMSE}=0.05752$ \\
$R_{\mathrm{S}}-P-T$ & Linear $\times Q_{10}$ & $R_{\mathrm{S}}=(0.002 \times P+1.16) \times 1.38^{\frac{T_{\text {surf }}-10}{10}}$ & $R_{\mathrm{S}}=(0.024 \times P+1.20) \times 1.08^{\frac{T_{\text {surf }}-10}{10}}$ \\
& & $R^{2}=0.98$ & $R^{2}=0.94$ \\
& & RMSE $=0.0491$ & $\mathrm{RMSE}=0.0408$ \\
\hline
\end{tabular}

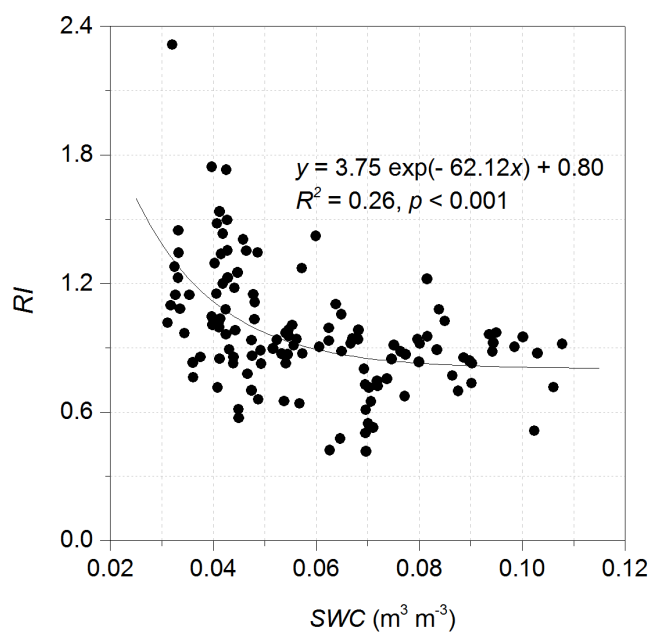

Figure 4. Relationship between soil water content (SWC) and the relative importance (RI) of soil-surface temperature and photosynthesis at an Artemisia ordosica-dominated site as a function of soil respiration $\left(R_{\mathrm{S}}\right)$.

manner, when $\mathrm{SWC}<0.08 \mathrm{~m}^{3} \mathrm{~m}^{-3}$ (ratio of $\mathrm{SWC}$ to soil porosity of 0.26 ; Fig. 6a). Hysteresis was not evident when SWC $>0.08 \mathrm{~m}^{3} \mathrm{~m}^{-3}$ (Fig. 6a). In contrast, diel hysteresis between $R_{\mathrm{S}}$ and photosynthesis was linearly related to SWC in an upward manner when $\mathrm{SWC}<0.08 \mathrm{~m}^{3} \mathrm{~m}^{-3}$ (Fig. 6b), but ceased to be related when $\mathrm{SWC}>0.08 \mathrm{~m}^{3} \mathrm{~m}^{-3}$ (Fig. 6b).

\section{Discussion}

\subsection{Degree of control of photosynthesis on diel hysteresis}

In our study, we found that the diurnal pattern in temperature $\left(T_{\mathrm{a}}, T_{\text {surf }}\right.$, and $\left.T_{\mathrm{s}}\right)$ lagged behind $R_{\mathrm{s}}$ by $0-4 \mathrm{~h}$, which resulted in a counterclockwise loop in the relationship between $R_{\mathrm{S}}$ and temperature. Although the magnitude of hys-
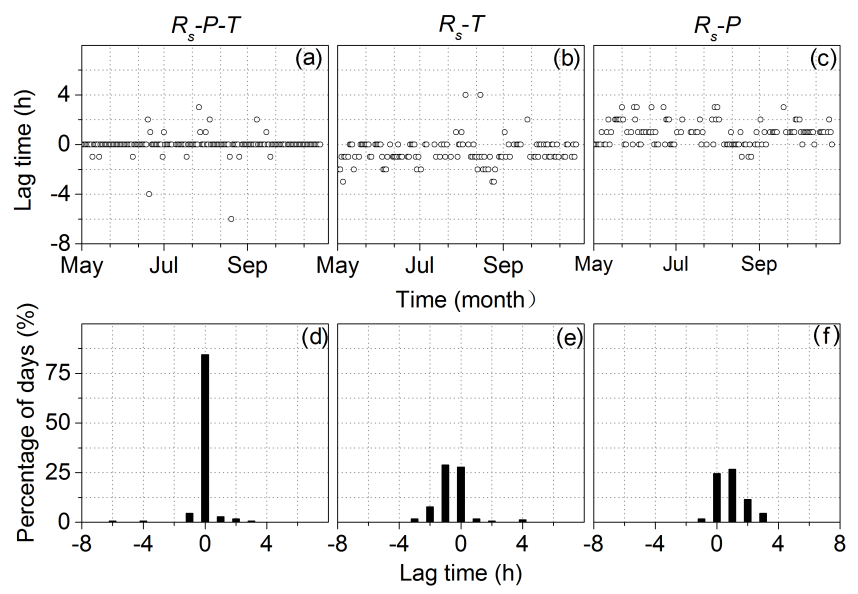

Figure 5. Time lags between measured and modeled soil respiration by means of soil-surface temperature and photosynthesis over the growing season; $R_{\mathrm{S}}-T$ function (Eq. 1), $R_{\mathrm{S}}-P$ function (Eq. 2), and $R_{\mathrm{S}}-P-T$ function (Eq. 3 ).

teresis between $R_{\mathrm{S}}$ and temperature differed among the three temperature measurements, their seasonal variation was generally uniform. Among the temperature measurements, $T_{\text {surf }}$ was more closely related to diel $R_{\mathrm{s}}$, resulting in weaker hysteresis. Magnitude of hysteresis between $R_{\mathrm{S}}$ and temperature was comparable to those in other plant systems, e.g., 3.5$5 \mathrm{~h}$ in a boreal aspen stand (Gaumont-Guay et al., 2006) and $0-5 \mathrm{~h}$ in a Chinese pine plantation (Jia et al., 2013). However, the direction of hysteresis was unlike that reported by Phillips et al. (2011), who had reported $R_{\mathrm{S}}$ lagging behind soil temperature.

In general, transfer of heat (downward) and gases (upward) through the soil complex by simple diffusion would take time to occur. Increased SWC would serve to impede this transfer (Millington and Quirk, 1961). If physical processes alone controlled hysteresis, you would expect $R_{\mathrm{S}}$ to lag behind $T_{\text {surf }}$ and hysteresis to increase with increasing 
SWC. However, such rationalization is not supported by our observations, which show $T_{\text {surf }}$ to lag behind $R_{\mathrm{S}}$ and hysteresis to decrease with increasing SWC. As a result, physical processes alone cannot account for the observed patterns in hysteresis between $R_{\mathrm{S}}$ and temperature. Combining photo-

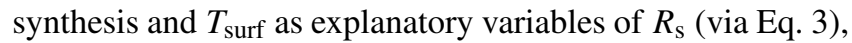
we found $84 \%$ of the days over the growing season had no observable lag between measured and modeled $R_{\mathrm{s}}$, relative to $27 \%$ of the days when $T_{\text {surf }}$ alone was used (associated with to Eq. 2), suggesting that photosynthesis has an important role in governing hysteresis in desert shrubland. Along with other studies, including those of Tang et al. (2005), Vargas and Allen (2008), Carbone et al. (2008), Kuzyakov and Gavrichkova (2010), and Wang et al. (2014), our findings provide increasing evidence of the role of photosynthesis in regulating diel hysteresis between $R_{\mathrm{S}}$ and temperature.

\subsection{Photosynthesis control of soil respiration and diel hysteresis}

The $0-4 \mathrm{~h}$ lag between $R_{\mathrm{S}}$ and photosynthesis observed is consistent with those observed in earlier studies, e.g., 0$4 \mathrm{~h}$ lag between ecosystem-level photosynthesis and $R_{\mathrm{S}}$ in a coastal wetland ecosystem (Han et al., 2014) and 0-3 h lag between plant photosynthesis and $R_{\mathrm{S}}$ in a steppe ecosystem (Yan et al., 2011). Short time lags suggest rapid response between recent photosynthesis and $R_{\mathrm{S}}$ (Kuzyakov and Gavrichova, 2010). This response is significantly faster than suggested in earlier studies, when approached from an isotopic or canopy/soil flux-based methodology (Howarth et al., 1994; Mikan et al., 2000; Jonson et al., 2002; Högberg et al., 2008; Kuzyakov and Gavrichova, 2010; Mencuccini and Hölttä, 2010; Kayler et al., 2010; Han et al., 2014).

According to the "goodness of fit" of Eq. (3) to the field data, the time lag between diel photosynthesis and $R_{\mathrm{S}}$ was likely caused by variations in temperature, regardless of SWC. Photosynthesis provide substrates to roots and rhizosphere microbes (Tang et al., 2005; Kuzyakov and Gavrichkova, 2010; Vargas et al., 2011; Han et al., 2014). Temperature directly drives enzymatic kinetics of respiratory metabolism in organisms (Van't Hoff, 1898; Lloyd and Taylor, 1994). Photosynthesis is directly driven by radiation (specifically, photosynthetically active radiation). Temperature is also driven by radiation, but through heating of the surface and subsequent air and soil layers. Thus, diel patterns in temperature continuously lagged behind those of photosynthesis by a few hours (as indicated in Fig. 2). The interactions between photosynthesis and temperature led $R_{\mathrm{S}}$ to lag behind photosynthesis, but temperature lagged behind $R_{\mathrm{S}}$ (Fig. 2). This sequence of events may explain the difference in the direction of hysteresis observed here, in contrast to that reported in Phillips et al. (2011). Such explanation is different from the explanations for forest ecosystems, where the transport of photosynthates and influence of turgor and osmotic pressure may be responsible for the specific coupling

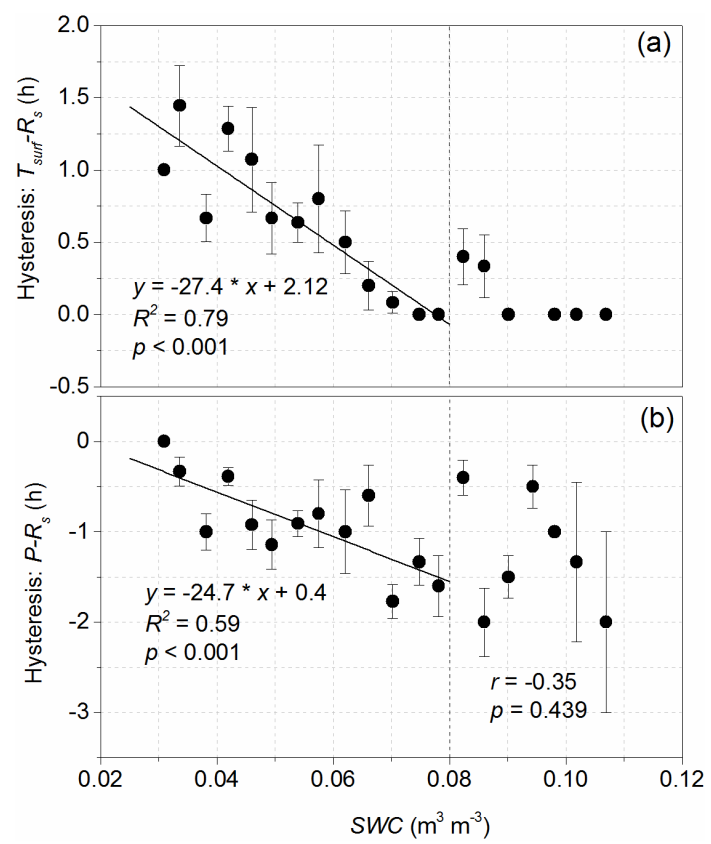

Figure 6. Time lags between soil respiration $\left(R_{\mathrm{S}}\right)$ and soilsurface temperature $\left(T_{\text {surf }}\right), R_{\mathrm{S}}$, and photosynthesis at an Artemisia ordosica-dominated site with respect to soil water content (SWC). Time lags were bin-averaged using SWC intervals of $0.004 \mathrm{~m}^{3} \mathrm{~m}^{-3}$.

observed between current photosynthesis and $R_{\mathrm{S}}$ (Steinmann et al., 2004; Högberg et al., 2008; Hölttä et al., 2006, 2009; Mencuccini and Hölttä, 2010). Variations in coupling dynamics may occur because of differences in vegetation height among ecosystems (Kuzyakov and Gavrichova, 2010; Mencuccini and Hölttä, 2010). Unlike forest ecosystems, lowstatured vegetation in shrub systems $(\sim 0.5 \mathrm{~m})$ may elicit a few minutes of delay in the transportation of photosynthates and influence of turgor and osmotic pressure (Kuzyakov and Gavrichkova, 2010). Such small time lags cannot be easily identified in hourly measurements, resulting in an apparent temperature-dominated control of photosynthesis and $R_{\mathrm{s}}$.

\subsection{Influences of soil water content on seasonal variation in diel hysteresis}

Diel $R_{\mathrm{S}}$ varied consistently with $T_{\text {surf }}$, with no observable signs of hysteresis, when SWC $>0.08 \mathrm{~m}^{3} \mathrm{~m}^{-3}$. However, as SWC decreased from this value, diel $R_{\mathrm{S}}$ varied more closely with photosynthesis, leading to increased diel hysteresis between $R_{\mathrm{S}}$ and $T_{\text {surf }}$. These results suggest that SWC played a more important role in regulating the relative control of photosynthesis and temperature on diel $R_{\mathrm{S}}$ over the growing season, supporting our second hypothesis.

A possible explanation for SWC regulating hysteresis might be associated with changes in substrate supply. During the wet period with $\mathrm{SWC}>0.08 \mathrm{~m}^{3} \mathrm{~m}^{-3}$, increases in SWC ameliorate diffusion of soil $\mathrm{C}$ substrates and its ac- 
cess to soil microbes (Curiel Yuste et al., 2003; Jarvis et al., 2007). Amount of substrate to roots and rhizosphere microbes is also expected to be high as a result of high current photosynthesis (Baldocchi et al., 2006). As a result, diel $R_{\mathrm{S}}$ is not limited by $\mathrm{C}$ substrates provided by current photosynthesis and soil organic matter. Consequences of diel $R_{\mathrm{S}}$ may vary repeatedly in synchrony with diel temperature, with no indication of hysteresis when SWC $>0.08 \mathrm{~m}^{3} \mathrm{~m}^{-3}$ (Fig. 6a). By contrast, during dry and hot phases, with SWC $<0.08 \mathrm{~m}^{3} \mathrm{~m}^{-3}$, inadequate soil water limits diffusion of soil C substrates and its access to soil microbes (Jassal et al., 2008) and also suppresses photosynthesis (supported by Fig. $2 \mathrm{~g}, \mathrm{~h}$ ). As a result, $R_{\mathrm{S}}$ may be limited by $\mathrm{C}$ substrates under dry conditions. It has been reported that current photosynthesis can account for about $65-70 \%$ of total $R_{\mathrm{S}}$ over the growing season (Ekblad and Högberg et al., 2001; Högberg et al., 2001). Thus, diel $R_{\mathrm{S}}$ may vary more closely to photosynthesis during dry and hot phases over the growing season (Fig. 2h), resulting in increased hysteresis with decreasing SWC below $0.08 \mathrm{~m}^{3} \mathrm{~m}^{-3}$ (Fig. 6b).

The $0.08 \mathrm{~m}^{3} \mathrm{~m}^{-3} \mathrm{SWC}$ threshold of this study was consistent with an earlier study by Wang et al. (2014) that reported that seasonal $R_{\mathrm{S}}$ decoupled from soil temperature as SWC fell below $0.08 \mathrm{~m}^{3} \mathrm{~m}^{-3}$. Earlier studies have reported similar responses of $R_{\mathrm{S}}$ to temperature (Palmroth et al., 2005; Jassal et al., 2008). For example, $R_{\mathrm{S}}$ in an 18-yearold temperate Douglas fir stand decoupled from $T_{\mathrm{S}}$ when SWC fell below $0.11 \mathrm{~m}^{3} \mathrm{~m}^{-3}$. Our results suggest that the decoupling of $R_{\mathrm{S}}$ from temperature for low SWC was due to a shift in control from temperature to photosynthesis. Our work provides urgently needed new knowledge concerning causes/mechanisms involved in defining variation in diel hysteresis in desert shrubland. Based on our work, we suggest that photosynthesis should be considered in simulations of diel $R_{\mathrm{S}}$ in drylands, especially when SWC falls below $0.08 \mathrm{~m}^{3} \mathrm{~m}^{-3}$.

\section{Conclusions}

Soil water content regulated the relative control between photosynthesis and temperature on diel $R_{\mathrm{S}}$ by changing the relative contribution of autotrophic and heterotrophic respiration to total $R_{\mathrm{S}}$, causing seasonal variation in diel hysteresis between $R_{\mathrm{S}}$ and temperature. Hysteresis was not observed between $R_{\mathrm{S}}$ and $T_{\text {surf }}$, when SWC $>0.08 \mathrm{~m}^{3} \mathrm{~m}^{-3}$, but the lag hours increased as SWC decreased below this SWC threshold. Incorporating photosynthesis into $R_{\mathrm{S}}$-temperature-based models reduces diel hysteresis and increases the overall level of goodness of fit. Our findings highlight the importance of biological mechanisms in diel hysteresis between $R_{\mathrm{S}}$ and temperature and the importance of SWC in plant photosynthesis-soil respiration dynamics in dryland ecosystems.
Data availability. The data are available at https://pan.baidu.com/ s/1o8yr4L0.

Competing interests. The authors declare that they have no conflict of interest.

Special issue statement. This article is part of the special issue "Ecosystem processes and functioning across current and future dryness gradients in arid and semi-arid lands". It is not associated with a conference.

Acknowledgements. We acknowledge the grants obtained from National Natural Science Foundation of China (NSFC; 31670710 , 31670708 and 31361130340), the National Key Research and Development Program of China (2016YFC0500905), the Fundamental Research Funds for the Central Universities (BLYJ201601 and 2015ZCQ-SB-02), and the Finnish-Chinese research collaboration project EXTREME (2013-2016) between Beijing Forestry University and University of Eastern Finland (EXTREME project 14921 funded by Academy of Finland). Also the US-China Carbon Consortium (USCCC) supported this work by way of helpful discussions and exchange of ideas. We acknowledge Paul Stoy, Associate Editor, and anonymous reviewers for their valuable comments and suggestions on this paper. We also acknowledge Huishu Shi, Yuming Zhang, Wei Feng, Yajuan Wu, Peng Liu, Qiang Yang, and Mingyan Zhang for their assistance with the field measurements and instrumentation maintenance.

Edited by: Paul Stoy

Reviewed by: two anonymous referees

\section{References}

Austin, A. T.: Has water limited our imagination for aridland biogeochemistry?, Trends Ecol. Evol., 26, 229-235, 2011.

Baldocchi, D., Tang, J., and Xu, L.: How switches and lags in biophysical regulators affect spatial-temporal variation of soil respiration in an oak-grass savanna, J. Geophys. Res.-Biogeo., 111, G02008, https://doi.org/10.1029/2005JG000063, 2006.

Barron-Gafford, G. A., Scott, R. L., Jenerette, G. D., and Huxman, T. E.: The relative controls of temperature, soil moisture, and plant functional group on soil $\mathrm{CO}_{2}$ efflux at diel, seasonal, and annual scales, J. Geophys. Res.-Biogeo., 116, G01023, https://doi.org/10.1029/2010JG001442, 2011.

Bahn, M., Schmitt, M., Siegwolf, R., Richter, A., and Brüggemann, N.: Does photosynthesis affect grassland soil-respired $\mathrm{CO}_{2}$ and its carbon isotope composition on a diurnal timescale?, New Phytol., 182, 451-460, 2009.

Carbone, M. S., Winston, G. C., and Trumbore, S. E.: Soil respiration in perennial grass and shrub ecosystems: Linking environmental controls with plant and microbial sources on seasonal and diel timescales, J. Geophys. Res.-Biogeo., 113, G02022, https://doi.org/10.1029/2007JG000611, 2008.

Curiel Yuste, J. C., Janssens, I. A., Carrara, A., Meiresonne, L., and Ceulemans, R.: Interactive effects of temperature and precipita- 
tion on soil respiration in a temperate maritime pine forest, Tree Physiol., 23, 1263-1270, 2003.

Davidson, E. A., Janssens, I. A., and Luo, Y. Q.: On the variability of respiration in terrestrial ecosystems: moving beyond $Q_{10}$, Glob. Change Biol., 12, 154-164, 2006.

Darenova, E., Pavelka, M., and Acosta, M.: Diurnal deviations in the relationship between $\mathrm{CO}_{2}$ efflux and temperature: A case study, Catena, 123, 263-269, 2014.

Ekblad, A. and Högberg, P.: Natural abundance of ${ }^{13} \mathrm{C}$ in $\mathrm{CO}_{2}$ respired from forest soils reveals speed of link between photosynthesis and root respiration, Oecologia, 127, 305-308, 2001.

Feng, W., Zhang, Y., Wu, B., Qin, S., and Lai, Z.: Influence of environmental factors on carbon dioxide exchange in biological soil crusts in desert areas, Arid Land Res. Manag., 28, 186-196, 2014.

Gaumont-Guay, D., Black, T. A., Griffis, T. J., Barr, A. G., Jassal, R. S., and Nesic, Z.: Interpreting the dependence of soil respiration on soil temperature and water content in a boreal aspen stand, Agr. Forest Meteorol., 140, 220-235, 2006.

Gaumont-Guay, D., Black, T. A., Barr, A. G., Jassal, R. S., and Nesic, Z.: Biophysical controls on rhizospheric and heterotrophic components of soil respiration in a boreal black spruce stand, Tree Physiol., 28, 161-171, 2008.

Gong, J., Jia, X., Zha, T., Wang, B., Kellomäki, S., and Peltola, H.: Modeling the effects of plant-interspace heterogeneity on waterenergy balances in a semiarid ecosystem, Agr. Forest Meteorol., 221, 189-206, 2016.

Han, G., Luo, Y., Li, D., Xia, J., Xing, Q., and Yu, J.: Ecosystem photosynthesis regulates soil respiration on a diurnal scale with a short-term time lag in a coastal wetland, Soil Biol. Biochem., 68, 85-94, 2014.

Högberg, P., Nordgren, A., Buchmann, N., Taylor, A. F. S., Ekblad, A., Högberg, M. N., Nyberg, G., Ottosson-Löfvenius, M., and Read, D. J.: Large-scale forest girdling shows that current photosynthesis drives soil respiration, Nature, 411, 789-792, 2001.

Högberg, P. and Read, D. J.: Towards a more plant physiological perspective on soil ecology, Trends Ecol. Evol., 21, 548-554, 2006.

Högberg, P., Högberg, M. N., Gottlicher, S. G., Betson, N. R., Keel, S. G., Metcalfe, D. B., Campbell, C., Schindlbacher, A., Hurry, V., Lundmark, T., Linder, S., and Näsholm, T.: High temporal resolution tracing of photosynthate carbon from the tree canopy to forest soil microorganisms, New Phytol., 177, 220-228, 2008.

Hölttä, T., Vesala, T., Sevanto, S., Perämäki, M., and Nikinmaa, E.: Modeling xylem and phloem water flows in trees according to cohesion theory and Münch hypothesis, Trees: Structure and Function, 20, 67-78, 2006.

Hölttä, T., Nikinmaa, E., and Mencuccini, M.: Linking phloem function to structure: analysis with a coupled xylem-phloem transport model, J. Theor. Biol., 259, 325-337, 2009.

Howarth, W. R., Pregitzer, K. S., and Paul, E. A.: ${ }^{14} \mathrm{C}$ allocation in tree soil systems, Tree Physiol., 14, 1163-1176, 1994.

Irvine, J., Law, B. E., and Kurpius, M. R.: Coupling of canopy gas exchange with root and rhizosphere respiration in a semi-arid forest, Biogeochemistry, 73, 271-282, 2005.

Jarvis, P., Rey, A., Petsikos, C., Wingate, L., Rayment, M., Pereira, J., Banza, J., David, J., Miglietta, F., Borghetti, M., Manca, G., and Valentini, R.: Drying and wetting of Mediterranean soil stim- ulates decomposition and carbon dioxide emission: the "Birch effect”, Tree Physiol., 27, 929-940, 2007.

Jassal, R. S., Andrew Black, T., Novak, M. D., Gaumont-Guay, D., and Nesic, Z.: Effect of soil water stress on soil respiration and its temperature sensitivity in an 18-year-old temperate Douglasfir stand, Glob. Change Biol., 14, 1305-1318, 2008.

Jia, X., Zhan, T., Wu, B., Zhang, Y., Chen, W., Wang, X., Yu, H., and He, G.: Temperature response of soil respiration in a Chinese pine plantation: hysteresis and seasonal vs. diel $Q_{10}$, PLoS ONE, 8, e57858, https://doi.org/10.1371/journal.pone.0057858, 2013.

Jia, X., Zha, T. S., Wu, B., Zhang, Y. Q., Gong, J. N., Qin, S. G., Chen, G. P., Qian, D., Kellomäki, S., and Peltola, H.: Biophysical controls on net ecosystem $\mathrm{CO}_{2}$ exchange over a semiarid shrubland in northwest China, Biogeosciences, 11, 4679-4693, https://doi.org/10.5194/bg-11-4679-2014, 2014.

Johnson, D., Leake, J. R., Ostle, N., Ineson, P., and Read, D. J.: In situ ${ }^{13} \mathrm{CO}_{2}$ pulse labelling of upland grassland demonstrates a rapid pathway of carbon flux from arbuscular mycorrhizal mycelia to soil, New Phytol., 153, 327-334, 2002.

Kayler, Z., Gessler, A., and Buchmann, N.: What is the speed of link between aboveground and belowground processes? New Phytol., 187, 885-888, 2010.

Kuzyakov, Y. and Gavrichkova, O.: Review: Time lag between photosynthesis and carbon dioxide efflux from soil: a review of mechanisms and controls, Glob. Change Biol., 16, 3386-3406, 2010.

Lange, O. L.: Photosynthesis of soil-crust biota as dependent on environmental factors, in: Biological soil crusts: structure, function, and management, edited by: Belnap, J. and Lange, O. L., Berlin: Springer, 217-40, 2003.

Liu, Q., Edwards, N. T., Post, W. M., Gu, L., Ledford, J., and Lenhart, S.: Temperature independent diel variation in soil respiration observed from a temperate deciduous forest, Glob. Change Biol., 12, 2136-2145, 2006.

Lloyd, J. and Taylor, J. A.: On the temperature dependence of soil respiration, Funct. Ecol., 8, 315-323, 1994.

Mencuccini, M. and Hölttä, T.: The significance of phloem transport for the speed with which canopy photosynthesis and belowground respiration are linked, New Phytol., 185, 189-203, 2010.

Mikan, C. J., Zak, D. R., Kubiske, M. E., and Pregitzer, K. S.: Combined effects of atmospheric $\mathrm{CO}_{2}$ and $\mathrm{N}$ availability on the belowground carbon and nitrogen dynamics of aspen mesocosms, Oecologia, 124, 432-445, 2000.

Millington, R. J. and Quirk, J. P.: Permeability of porous solids, T. Faraday Soc., 57, 1200-1207, 1961.

Noy-Meir, I.: Desert ecosystems: environment and producers, Annu. Rev. Ecol. Syst., 4, 25-51, 1973.

Oikawa, P. Y., Grantz, D. A., Chatterjee, A., Eberwein, J. E., Allsman, L. A., and Jenerette, G. D.: Unifying soil respiration pulses, inhibition, and temperature hysteresis through dynamics of labile soil carbon and $\mathrm{O}_{2}$, J. Geophys. Res.-Biogeo., 119, 521-536, 2014.

Palmroth, S., Maier, C. A., McCarthy, H. R., Oishi, A. C., Kim, H.-S., Johnsen, K. H., Katul, G. G., and Oren, R.: Contrasting responses to drought of forest floor $\mathrm{CO}_{2}$ efflux in a Loblolly pine plantation and a nearby Oak-Hickory forest, Glob. Change Biol., 11, 421-434, 2005. 
Phillips, C. L., Nickerson, N., Risk, D., and Bond, B. J.: Interpreting diel hysteresis between soil respiration and temperature, Glob. Change Biol., 17, 515-527, 2011.

Poulter, B., Frank, D., Ciais, P., Myneni, R. B., Andela, N., Bi, J., Broquet, G., Canadell, J. G., Chevallier, F., Liu, Y. Y., Running, S. W., Sitch, S., and Van der Werf, G. R.: Contribution of semiarid ecosystems to interannual variability of the global carbon cycle, Nature, 509, 600-603, 2014.

Riveros-Iregui, D. A., Emanuel, R. E., Muth, D. J., McGlynn, B. L., Epstein, H. E., Welsch, D. L., Pacific, V. J., and Wraith, J. M.: Diurnal hysteresis between soil $\mathrm{CO}_{2}$ and soil temperature is controlled by soil water content, Geophys. Res. Lett, 34, L17404, https://doi.org/10.1029/2007GL030938, 2007.

Ruehr, N. K., Offermann, C. A., Gessler, A., Winkler, J. B., Ferrio, J. P., Buckmann, N., and Barnard, R. L.: Drought effects on allocation of recent carbon: from beech leaves to soil $\mathrm{CO}_{2}$ efflux, New Phytol., 184, 950-961, 2009.

Safriel, U. and Adeel, Z.: Dryland ecosystems, II, in: Ecosystems and human well-being: current state and trends, Vol. 1, edited by: Hassan, R., Scholes, R., and Neville, A., Island Press, Washingon, DC, 623-662, 2005.

Sampson, D. A., Janssens, I. A., Curiel Yuste, J., and Ceulemans, R.: Basal rates of soil respiration are correlated with photosynthesis in a mixed temperate forest, Glob. Change Biol., 13, 20082017, 2007.

Song, W., Chen, S., Zhou, Y., Wu, B., Zhu, Y., Lu, Q., and Lin, G.: Contrasting diel hysteresis between soil autotrophic and heterotrophic respiration in a desert ecosystem under different rainfall scenarios, Sci. Rep., 5, 16779, https://doi.org/10.1038/srep16779, 2015a.

Song, W., Chen, S., Wu, B., Zhu, Y., Zhou, Y., Lu, Q., and Lin, G.: Simulated rain addition modifies diurnal patterns and temperature sensitivities of autotrophic and heterotrophic soil respiration in an arid desert ecosystem, Soil Biol. Biochem., 82, 143-152, $2015 b$.

Steinmann, K., Siegwolf, R. T. W., Saurer, M., and Körner, C.: Carbon fluxes to the soil in a mature temperate forest assessed by ${ }^{13} \mathrm{C}$ isotope tracing, Oecologia, 141, 489-501, 2004.

Stoy, P. C., Palmroth, S., Oishi, A. C., Siqueira, M. B. S., Juang, J-Y., Novick, K. A., Ward, E. J., Katul, G. G., and Oren, R.: Are ecosystem carbon inputs and outputs coupled at short time scales? A case study from adjacent pine and hardwood forests using impulse-response analysis, Plant Cell Environ., 30, 700-710, 2007.
Tang, J., Baldocchi, D. D., and Xu, L.: Tree photosynthesis modulates soil respiration on a diurnal time scale, Glob. Change Biol., 11, 1298-1304, 2005.

Van't Hoff, J. H.: Lectures on Theoretical and Physi-cal Chemistry. Part I. Chemical Dynamics (translated by R. A. Lehfeldt), Edward Arnold, London, 224-229, 1898.

Vargas, R. and Allen, M. F.: Environmental controls and the influence of vegetation type, fine roots and rhizomorphs on diel and seasonal variation in soil respiration, New Phytol., 179, 460-471, 2008.

Vargas, R., Baldocchi, D. D., Bahn, M., Hanson, P. J., Hosman, K. P., Kulmala, L., Pumpanen, J., and Yang, B.: On the multitemporal correlation between photosynthesis and soil $\mathrm{CO}_{2}$ efflux: reconciling lags and observations, New Phytol., 191, 10061017, 2011.

Wang, B., Zha, T. S., Jia, X., Wu, B., Zhang, Y. Q., and Qin, S. G.: Soil moisture modifies the response of soil respiration to temperature in a desert shrub ecosystem, Biogeosciences, 11, 259-268, https://doi.org/10.5194/bg-11-259-2014, 2014.

Wang, B., Zha, T. S., Jia, X., Gong, J. N., Wu, B., Bourque, C. P. A., Zhang, Y., Qin, S. G., Chen, G. P., and Peltola, H.: Microtopographic variation in soil respiration and its controlling factors vary with plant phenophases in a desert-shrub ecosystem, Biogeosciences, 12, 5705-5714, https://doi.org/10.5194/bg-125705-2015, 2015.

West, N. E., Stark, J. M., Johnson, D. W., Abrams, M. M., Wight, J. R., Heggem, D., and Peck, S.: Effects of climatic-change on the edaphic features of arid and semiarid lands of western North America, Arid Land Res. Manag., 8, 307-355, 1994.

Winkler, J. P., Cherry, R. S., and Schlesinger, W. H.: The $Q_{10}$ relationship of microbial respiration in a temperate forest soil, Soil Biol. Biochem., 28, 1067-1072, 1996.

Yan, L., Chen, S., Huang, J., and Lin, G.: Water regulated effects of photosynthetic substrate supply on soil respiration in a semiarid steppe, Glob. Change Biol. 17, 1990-2001, 2011.

Zhang, Q., Katul, G. G., Oren, R., Daly, E., Manzoni, S., and Yang, D.: The hysteresis response of soil $\mathrm{CO}_{2}$ concentration and soil respiration to soil temperature, J. Geophys. Res.-Biogeo., 120, 1605-1618, 2015. 